\title{
Mental performance in 8-year-old children fed reduced protein content formula during the 1st year of life: safety analysis of a randomised clinical trial
}

\author{
J. Escribano ${ }^{1}$, V. Luque ${ }^{1}$, J. Canals-Sans ${ }^{2}$, N. Ferré ${ }^{1}$, B. Koletzko ${ }^{3}$, V. Grote ${ }^{3}$, M. Weber ${ }^{3}$, D. Gruszfeld ${ }^{4}$, \\ K. Szott ${ }^{4}$, E. Verduci ${ }^{5}$, E. Riva ${ }^{5}$, G. Brasselle ${ }^{6}$, P. Poncelet $^{7}$ and R. Closa-Monasterolo ${ }^{1 *}$ \\ for the EU Childhood Obesity Project Group \\ ${ }^{1}$ Pediatrics Research Unit, Faculty of Medicine, Universitat Rovira i Virgili, IISPV, Reus, 43201, Spain \\ ${ }^{2}$ Research Centre for Behavioural Assessment (CRAMC), Universitat Rovira i Virgili, IISPV, Tarragona, 43007, Spain \\ ${ }^{3}$ Division of Nutritional Medicine and Metabolism, Hauner Children's Hospital, University of Munich Medical Centre, Munich, \\ 80337, Germany \\ ${ }^{4}$ Neonatal Intensive Care Unit and Department of Gastroenterology, Hepatology and Eating Disorders, Children's Memorial \\ Health Institute, Warsaw, 04730, Poland \\ ${ }^{5}$ Department of Paediatrics, San Paolo Hospital, University of Milan, Milan, 20142, Italy \\ ${ }^{6}$ Department of Paediatrics, CHC St Vincent, Liège-Rocourt, 4000, Belgium \\ ${ }^{7}$ Department of Paediatrics, University Children's Hospital Queen Fabiola, Université Libre de Bruxelles, Brussels, Belgium
}

(Submitted 12 August 2014 - Final revision received 14 January 2015 - Accepted 16 February 2015)

\section{Abstract}

In humans, maximum brain development occurs between the third trimester of gestation and 2 years of life. Nutrition during these critical windows of rapid brain development might be essential for later cognitive functioning and behaviour. In the last few years, trends on protein recommendations during infancy and childhood have tended to be lower than that in the past. It remains to be demonstrated that lower protein intakes among healthy infants, a part of being able to reduce obesity risk, is safe in terms of mental performance achievement. Secondary analyses of the EU CHOP, a clinical trial in which infants from five European countries were randomised to be fed a higher or a lower protein content formula during the 1st year of life. Children were assessed at the age of 8 years with a neuropsychological battery of tests that included assessments of memory (visual and verbal), attention (visual, selective, focused and sustained), visual-perceptual integration, processing speed, visual-motor coordination, verbal fluency and comprehension, impulsivity/inhibition, flexibility/shifting, working memory, reasoning, visual-spatial skills and decision making. Internalising, externalising and total behaviour problems were assessed using the Child Behaviour Checklist 4-18. Adjusted analyses considering factors that could influence neurodevelopment, such as parental education level, maternal smoking, child's gestational age at birth and head circumference, showed no differences between feeding groups in any of the assessed neuropsychological domains and behaviour. In summary, herewith we report on the safety of lower protein content in infant formulae (closer to the content of human milk) according to long-term mental performance.

Key words: Protein: Metabolic programming: Mental performance: Infants

In humans, the critical window of brain development is between the third trimester of gestation and 2 years of age ${ }^{(1)}$. Intra-uterine and neonatal insults have long-term detrimental effects on neurodevelopmental outcomes ${ }^{(2,3)}$, which are not regulated only genetically. It is known that nutrients regulate brain development during gestation and early postnatal life ${ }^{(4,5)}$. Therefore, early nutrition during these critical windows of rapid brain development might be essential for later cognitive functioning and behaviour. Nutritional insults and malnutrition in early periods may affect brain cell proliferation and differentiation, synaptogenesis or dendritic arborisation and myelination, processes that are in turn associated with delays in cognitive functions ${ }^{(3)}$.

There is compelling evidence relating nutrient supply and nutritional status in early life with mental performance. However, some nutrients appear to have a stronger effect on brain development during gestation and early infancy, such as

Disclaimer: This paper was published as part of a supplement to British Journal of Nutrition, publication of which was supported partially by UNILEVER, NUTRIMENTHE EU Project and an unrestricted educational grant from the University of Granada. The papers included in this supplement were invited by the Guest Editor and have undergone the standard journal formal review process. They may be cited.

Abbreviations: BF, breast-fed; HP, higher protein; LP, lower protein.

* Corresponding author: R. Closa-Monasterolo, fax +34977 759 322, email ricardo.closa@urv.cat 
protein, Fe, Zn, Se, folates ${ }^{(5)}$, long-chain $\mathrm{PUFA}^{(6)}$ and vitamin $\mathrm{D}^{(7)}$, among others.

Classical models to study the effects of nutrition on later mental performance are nutritional intervention studies in preterm infants, who are within a critical period vulnerable to suboptimal early nutrition in terms of brain development. A clinical trial performed in 360 preterm infants, who were randomised to a preterm enriched formula (higher energy, protein and fat) or a standard term formula, showed that infants who were nutrient supplemented had improved intelligence quotients at $7 \cdot 5-8$ years of life $e^{(8)}$.

Other models relating nutrient supply and nutritional status to later cognitive function were usually observational or interventional studies on under-nourished children in developing countries. Studies providing energy and protein supplementation to under-nourished children showed benefits on their development, suggesting that this may be attributed to energy and protein supplementation rather than to micronutrients ${ }^{(9,10)}$. A study conducted in Guatemala demonstrated that infants exposed to a protein-energy supplementation (during gestation and the first 2 years of life) scored significantly better in knowledge, numeracy, reading, vocabulary, time-reaction in information-processing tasks during adolescence than those who were not supplemented ${ }^{(11)}$. Moreover, when these children were followed-up 20 years later, the authors found a better educational achievement among those who received protein supplementation in infancy compared with those who received energy supplementation ${ }^{(12)}$.

Regarding well-nourished infants, there are no data from large prospective follow-up studies on the possible effect of different levels of protein intake early in life on later neurodevelopment. In the last few years, trends on protein recommendations during infancy and childhood have tended to be lower than that in the past, as shown by a significant reduction recommended by the last WHO and the FAO Joint Report ${ }^{(13)}$.

The Childhood Obesity Project, a randomised clinical trial conducted in well-nourished infants from five European countries, showed that lower protein (LP) formula intake during the 1st year of life led to significant lower BMI at $2^{(14)}$ and 6 years ${ }^{(15)}$ of age. Formulae provided to infants during the 1 st year of life were both within the normal ranges recommended by the EU Directive for Infant and the Follow-on Formulae ${ }^{(16)}$. However, variability in normal diets among healthy infants may lead to significantly different protein intakes.

It remains to be demonstrated whether LP intakes (within the normal ranges) among healthy infants, a part of being able to reduce obesity risk, are safe in terms of mental performance achievement.

Our aim was to demonstrate that LP content in infant formulae during the 1st year of life does not affect cognition and behaviour later in childhood compared with higher protein (HP) formulae intake.

\section{Methods}

Design

This study was a European multi-centre randomised clinical trial, in which infants were randomised to be fed a HP (infant formula $2.9 \mathrm{~g}$ protein $/ 418.4 \mathrm{~kJ}$ (100 kcal) and follow-on formula $4.4 \mathrm{~g}$ protein $/ 100 \mathrm{ml}$ ) or LP content formula (infant formula $1.77 \mathrm{~g}$ protein $/ 418.4 \mathrm{~kJ}(100 \mathrm{kcal})$ and follow-on formula $2.2 \mathrm{~g}$ protein $/ 100 \mathrm{ml}$ ) during the 1 st year of life, and were followedup at the age of 8 years with a neuropsychological battery of tests as a part of the Nutrimenthe Project. Details about the nutritional intervention have been published elsewhere ${ }^{(14)}$. An observational control group of breast-fed (BF) infants was recruited for comparison, as recommended by the European Society of Pediatric Gastroenterology Hepatology and Nutrition ${ }^{(17)}$, and were followed-up until the age of 8 years accordingly. Children were recruited by the research teams in clinics from Germany, Belgium, Italy, Poland and Spain during the 1st 8 weeks of life from October 2002 to July 2004. In brief, inclusion criteria were that infants should be born at term, should be healthy with appropriate weight and should not have disorders or medications altering growth and/or feeding. Formula-fed infants had to be exclusively formula-fed at the end of the 8th week of life. BF children had to be exclusively BF since birth (and abandonment of exclusive breast-feeding before the 3 months was a criterion to discontinue).

The growth of children was assessed until the age of 6 years $^{(15)}$. At 8 years of age, all the participants who had not expressed previously their willingness to not be contacted were approached by telephone to be invited for an additional visit.

\section{Neuropsychological assessment}

A neuropsychological battery of tests was carried out in children from the five European countries at the age of 8 years. Table 1 shows the tests used to assess the different domains.

Psychologists from the different countries were trained and provided with Standard Operating Procedures Manuals.

The Recall of Objects Test was used to assess visual memory in short term and long term ${ }^{(18)}$. This test has a reliability of 0.74 from 4 to 17 years. In this test, the child was asked to look at a sheet with different pictures for $20 \mathrm{~s}$. The child was then asked to recall the objects immediately (short-term memory) and after 20 min (delayed memory). After this, the child was asked to recognise the drawings in a sheet of paper (recognition). Hits, intrusions and perseverances were recorded at the different trials. Immediate visual memory score (hits 1st part-(intrusions 1st part + perseverances 1st part)) and delayed visual memory score (hits 2nd part-(intrusions 2nd part + perseverances 2nd part)) were calculated.

The Rey Auditory Verbal Learning Test ${ }^{(19)}$ was administered to assess verbal memory. To pass this test, the examiner read lists of words that the child had to remember and repeat (in the short term, long term and as recognition). Hits, intrusions and perseverances were recorded at the different trials. There was a 1 st part in which learning and attention was assessed, a 2nd part in which an interference list of words was included and a 3rd and 4th part in which short-term and long-term verbal memory were assessed, respectively. Overall learning achievement, loss after interference and loss after temporal delay were calculated. Total perseverances, intrusions and interferences were summarised. Test-re-test correlation coefficients ranged from 0.36 to 0.68 . The Cronbach's $\alpha$ coefficient was $0 \cdot 80^{(20)}$ The validity of 
Table 1. Neuropsychological battery of tests passed at 8 years of age

\begin{tabular}{|c|c|c|}
\hline Domain & Function & Test \\
\hline Memory & $\begin{array}{l}\text { Visual episodic memory } \\
\text { Verbal memory }\end{array}$ & $\begin{array}{l}\text { Recall of Objects Test (short and long-term memory) } \\
\text { Rey Auditory Verbal Learning Test } \\
{ }^{(19)}\end{array}$ \\
\hline Attention & $\begin{array}{l}\text { Sustained and focused attention } \\
\text { Spatial attention }\end{array}$ & $\begin{array}{l}\text { Continuous Performance Test } \\
\text { Cancellation test (Tachar) of Woodcook-Muñoz } \\
\text { (21-23) }\end{array}$ \\
\hline Perception & Visual-perceptual integration & Hooper Visual Organisation Test ${ }^{(24)}$ \\
\hline Language & $\begin{array}{l}\text { Semantic fluency } \\
\text { Verbal comprehension }\end{array}$ & $\begin{array}{l}\text { Animals - FAS } \\
\text { Nepsy's Token Test (NEPSY-II) } \\
(25,26)\end{array}$ \\
\hline Processing speed & Processing speed & Symbol digit modalities test ${ }^{(27)}$ \\
\hline Motor & Visual-motor coordination & Grooved Pegboard ${ }^{(28)}$ \\
\hline Executive functions & $\begin{array}{l}\text { Impulsivity/inhibition, selective attention } \\
\text { Flexibility/shifting } \\
\text { Working memory } \\
\text { Reasoning } \\
\text { Selective and focused attention } \\
\text { Visual-spatial skills } \\
\text { Flexibility/shifting }\end{array}$ & $\begin{array}{l}\text { Stroop (1st-3rd condition) })^{(29)} \\
\text { Stroop (4th condition) }{ }^{(29)} \\
\text { Reversal Digits (W-M) } \\
\text { Kaufman- ABC II Pattern reasoning } \\
\text { Children's Colour Trail Test } \\
{ }^{(31)}\end{array}$ \\
\hline & Decision making & Hungry Donkey Task ${ }^{(32)}$ \\
\hline
\end{tabular}

this test is supported for its correlation with similar tools from 0.50 to $0.65^{(19)}$

The Continuous Performance Test $(\mathrm{CPT})^{(21,22)}$ was used to assess sustained attention. To perform this task, the child was asked to press a computer key every time a yellow $A$ appeared on the screen, but not to press the key if any other letter in any other colour appeared (during 11' 39". Hits, commissions and omissions were recorded at every different trial. The median test-re-test correlation of the CPT has been $0 \cdot 67$, suggesting a good level of reliability.

The Cancellation Test ${ }^{(23-25)}$ was used to assess visual attention and processing speed, asking the child to mark five figures that should be equal to a model in a template that included several models. The child had $3 \mathrm{~min}$ to find as many equal figures as possible. Hits, commissions and omissions were recorded. The reliability of the Cancellation test for processing speed was 0.91 and for visual-spatial thinking it was $0.80^{(26)}$.

The Hooper Visual Organisation Test (HVOT) ${ }^{(27)}$ was administered to assess visual-perceptual integration. The test consisted of thirty line drawings, each showing a common object that had been cut into several pieces. The pieces were scattered on the page like parts of a puzzle. The child's task was doing a mental puzzle, telling where the object would be if the pieces were put back together correctly. Each recognised object was a hit. The coefficient alpha for the HVOT was 0.882, and the interrater reliabilities ranged from 0.977 to $0.992^{(28)}$.

The Animals test assessed verbal fluency at the semantic level, asking the child to state as many animals' names (hits) as possible.

The Nepsy's Token Test ${ }^{(29,30)}$ consisted of giving instructions to the child to mark on a figures template in order to assess the verbal comprehension (with each correct mark considered a hit). The validity of the Nepsy's token test has been shown by comparison with many tests such as the Wechsler Intelligence Scale for Children, fourth edition (WISC-IV; Wechsler, $2003)^{(29,30)}$

The Symbol Digit Modalities Test ${ }^{(31)}$ consisted of asking the child to relate symbols with numbers following a given template with a reference key during a limited time period (90 s).
Hits were recorded. We used this test to assess processing speed. This test has shown a test-re-test reliability of $0 \cdot 80^{(31)}$.

The Grooved Pegboard Test ${ }^{(32)}$ consisted of asking the child to place pegs in holes as fast as possible. The child needed to ascertain the proper orientation of the peg to place it in the hole; therefore, this task helped determine visual-motor coordination. For each hand, (dominant/non-dominant) three scores were recorded: the total time for completing the test (s), total number of pegs dropped and the total number of pegs correctly placed in the board.

The Stroop Test ${ }^{(33)}$ was used to assess reading fluency, selective attention and impulsivity/inhibition by asking the child (1st) to read as fast as possible the name of colours that appear written in black (hits), (2nd) to state the colour of coloured crosses that were shown (hits) and (3rd) to state the name of the colour that was written but coloured in a different colour (hits). Flexibility/shifting were then estimated through an interference index. The interference measure was calculated by subtracting the average time needed to complete the 1st two subtasks from the time needed to complete the third subtask (Interference $=$ time 3 rd task-(time 1 st task $\times$ time 2 nd task)/(time 1 st task + time 2 nd task))). This test has shown reliabilities between 0.73 and $0.89^{(33)}$

The Reversal Digits task (of Woodcook-Muñoz battery of tests) ${ }^{(25)}$ was used to assess Working memory (attention + hearing short-term memory) by asking the child to repeat in inverse order the lists of numbers that the examiner called out. Every correct answer was recorded as a hit. This test has a median reliability of $0 \cdot 88^{(25)}$.

Reasoning was assessed using the Kaufman-ABC II test ${ }^{(34)}$, by showing the child a series of images that formed a logical linear pattern, in which a part of the image was missing. The child should select the missing part from several options. Every correct image chosen was recorded as a hit. This test has shown an internal consistency of 0.89 and a test-re-test reliability of $0.74^{(34)}$.

The Children's Colour Trail Test ${ }^{(35)}$ consisted of linking numbers considering its colours including interferences to assess the child's flexibility/shifting; time taken was recorded 
(the faster the child was, the better the performance). Cognitive flexibility was calculated by subtracting the time to perform the 1st part from the time to perform the 2nd part of the test. The interference index was also calculated (Interference index $=($ time 2 nd part-time 1 st part)/time 1st part) (higher the interference index, lower the inhibitory control). The temporal test-re-test reliability of this test was modest (from 0.46 to $0 \cdot 60$ ). The concurrent validity from correlation with other tests ranges from 0.59 to $0.74^{(35)}$.

The Hungry Donkey Task (HDT) ${ }^{(36)}$ was performed to assess the child's decision-making abilities. This was a computer-based test in which a donkey chose from four doors, each with a trend to cost an apple or get rewarded with apples (red or green apples). The objective was to fetch the donkey the maximum number of green apples as possible. The task consisted of four parts in which hits were recorded. The total score was calculated as the sum of hits from the four parts.

\section{Behaviour}

The degree of internalising and externalising behavioural problems was assessed by administering the mothers with the Child Behaviour Checklist $4-18(\mathrm{CBCL})^{(37,38)}$. CBCL has a good reliability with internal coefficients ranging from 0.78 to 0.97 on the Syndrome scales and 0.72 to 0.91 on the DSM-Oriented scales $^{(37,38)}$. $Z$-scores were calculated using the references for societies $^{(37)}$.

\section{Perinatal characteristics}

At recruitment, perinatal characteristics such as gestational age, mother's age at child birth and delivery type were obtained from hospital records, and data regarding smoking habits (yes/ no), alcohol consumption (yes/no) and stress during pregnancy (yes/no) were obtained from the mothers through a questionnaire at the time of recruitment.

\section{Socio-demographic factors}

Nationality (foreign/not foreign) and the mother's marital status (single mother/mother married or living in partnership) were recorded through a questionnaire at recruitment. Information regarding parents' highest educational level was collected from the participants at the time of recruitment and recorded according to the International Standard Classification of Education - ISCED-97 ${ }^{(39)}$, and classified as low (pre-preliminary and primary level of education), medium (secondary and postsecondary level of education) and high (tertiary level of education).

\section{Ethics}

This study was carried out according to the Declaration of Helsinki ${ }^{(40)}$, and was approved by ethics committees of all the study centres. Parents or legal caregivers signed the written informed consents to participate in the study.

\section{Statistics}

As there were socio-cultural differences between countries, we calculated sex and country internal $Z$-scores for all the tests. All the results are presented as $Z$-scores. Descriptive results are presented as median and interquartile range; 25th, 75th percentiles.

Differences between LP and HP groups were assessed using the Student $t$ test or the Mann-Whitney $U$ test (as appropriate) after assessing data distribution. To compare the two randomised groups (LP and HP) with the observational group (BF), we used ANOVA or the Kruskal-Wallis test with Bonferroni post hoc comparisons (as appropriate).

We performed adjusted analyses using ANCOVA or the Mann-Whitney $U$ test (as appropriate) with correction for multiple testing (Bonferroni post hoc comparisons) to assess differences by feeding groups. Considered confounders were sex, parents' education level (low, medium, high), delivery type (vaginal $v$. caesarean section), gestational age, child's head circumference at birth $\left(Z\right.$-score referred to WHO standards ${ }^{(41)}$, calculated with WHO Anthro software for $\left.\mathrm{PC}^{(42)}\right)$ and at 8 years of age $(\mathrm{cm})$, maternal smoking during pregnancy or any other time, mother's age and marital status (single $v$. married) at the time of child birth and parents' nationality (both parents foreign/not foreign).

Statistical significance was accepted at $P<0 \cdot 05$. The data management and statistical analyses were conducted using IBM SPSS, version 20.0 (IBM Corp.).

\section{Results}

A total of 1678 infants were recruited in the five European countries ( $550 \mathrm{HP}, 540 \mathrm{LP}$ and $588 \mathrm{BF}$ ) (Fig. 1). The median age at inclusion to formula groups was $14 \mathrm{~d}$ (interquartile range: 3-30 d). At 12 months of age, 1099 children still remained in the study. Of the 652 participants included in the study at 8 years of age, 537 (82.4\%) (Fig. 1) agreed to be assessed with the neuropsychological battery of tests, which required approximately $2 \mathrm{~h}$ of participation.

Children in the formula-fed groups who had withdrawn from the study or did not take part in the neuropsychological assessment at 8 years of age did not differ from the children who took part in some of the baseline characteristics such us birth weight, birth length, gestational age and maternal stress during pregnancy (data not shown).

Children who withdrew from the study had bigger head circumference at birth $(34.3$ (SD 1.3) v. 34.1 (SD 1.4), $P=0.039)$ and younger mothers (29.3 (sD 5.4) v. 30.9 (SD 4.8), $P<0.001$ ) compared with children in the study at 8 years of age, but leaving the study did not interact with the study formula. Children who participated in the study were born more frequently by caesarean section $(28.5 v .19 .8 \%, P=0.001)$, had foreign parents more frequently $(8.0 \mathrm{v} .6 .7 \%, P<0.001)$, had fewer parents with low education level (14.5 v. $26 \cdot 1 \%$, $P<0.001)$, had single mothers less frequently $(7.7 v .4 .5 \%$, $P=0.030$ ), had mothers who smoked less frequently until the 12th week of gestation $(24.4 v .36 .9 \%, P<0.001)$ and beyond (21.9 v. 31.5\%,P=0.001) and had mothers who 


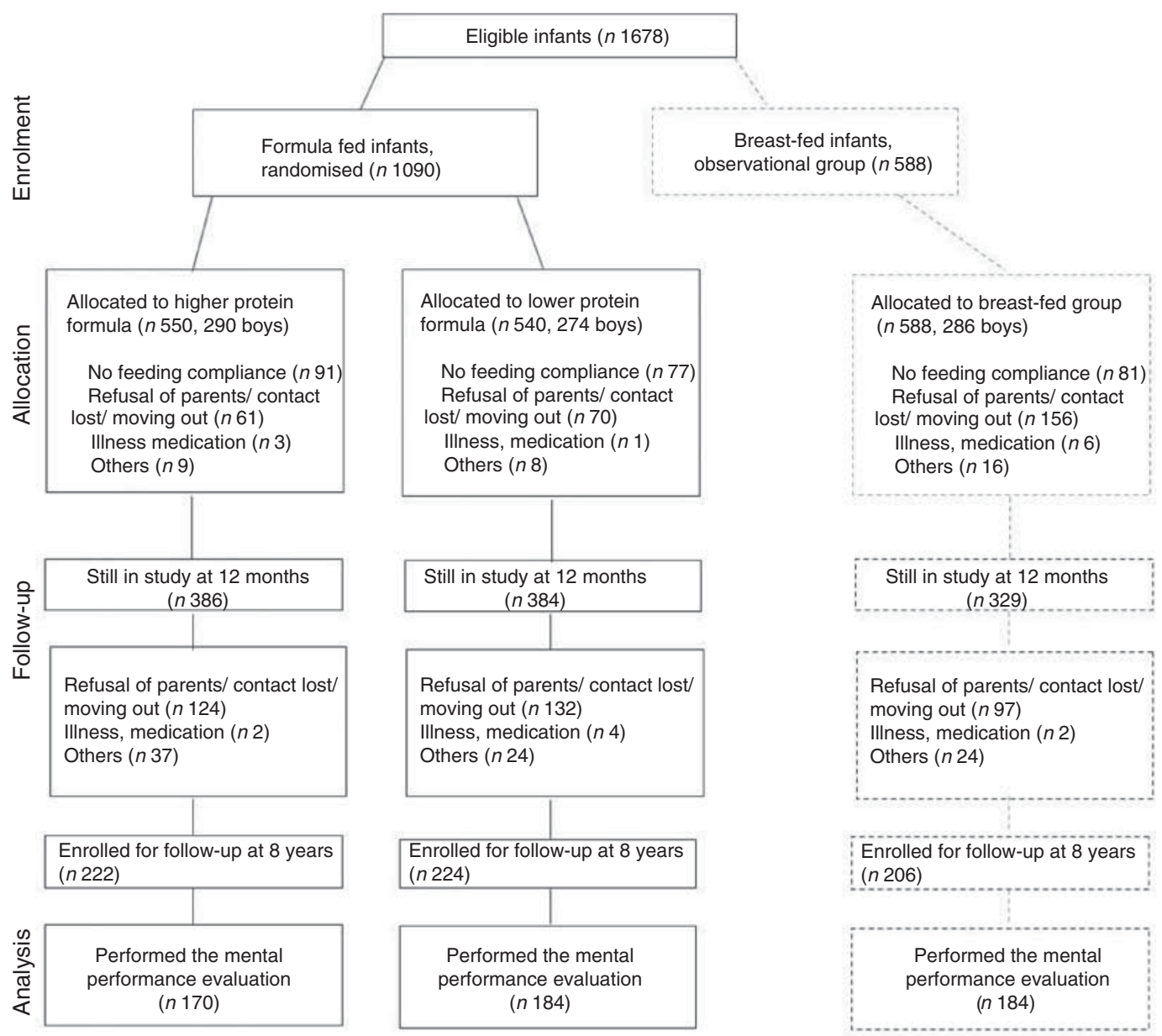

Fig. 1. Flow chart of participants from inclusion up to 8 years of age.

drank alcohol during pregnancy more frequently (25.4 $v$. $16.2 \%, P<0.001)$.

Table 2 shows the perinatal baseline characteristics of the study sample by feeding group at 8 years of age. Children fed the LP and HP formulae had similar baseline characteristics at inclusion, as there were no differences in anthropometrical, socio-demographic characteristics, gestational age and mother's age at child birth between them. Children fed the LP formula were born in higher proportion by caesarean section $(P=0.020)$ and their mothers smoked more frequently $(P=0.009$, for tobacco before and beyond 12th week of gestation) compared with infants fed the HP formula.

BF infants significantly differed from formula-fed infants in several baseline characteristics such as gestational age, delivery type, maternal education, maternal age and maternal smoking habits (Table 2).

Figure 2 shows the main results for LP- and HP-fed children for all the assessed domains ( $Z$-scores). There were no statistically significant differences between feeding groups in any of the assessed domains such as visual memory (neither immediate nor delayed), verbal memory (both in the short and the long term as well as immediate and delayed free recall), visual attention, sustained attention, visual-perceptual integration, processing speed, visual-motor coordination, verbal comprehension, verbal fluency, impulsivity/inhibition, selective attention, flexibility/shifting, working memory, reasoning, selective and focused attention, visual-spatial skills, decision making and any of the behaviour scales assessed with CBCL (internalising problems, externalising problems or total problems).

We performed adjusted analyses, considering factors that could influence neurodevelopment, such as parental education level and nationality, mother's age and marital status, maternal smoking, child's gestational age at birth, delivery type and head circumference at birth and at 8 years of age. These adjusted analyses confirmed no differences in any of the neuropsychological domains and behaviour between 8-year-old children fed the higher or the LP formula during the 1st year of life.

Unadjusted analyses comparing children who had been $\mathrm{BF}$ for at least 3 months showed similar behaviour and performance in all the domains compared with the HP and LP children (data not shown), except for the HDT (decision making), which was worse in the BF group (0.123 (95\% CI $-0.839,0.512))$ than in the HP group $(0.320$ (95\% CI -0.308 , $0 \cdot 621)$ ) ( $P=0 \cdot 048)$. Adjusted analyses including the confounders mentioned above discarded any significant difference. 
Table 2. Anthropometric baseline characteristics of the children assessed with the neuropsychological battery of tests at 8 years of age (Mean values and standard deviations; frequencies and percentages)

\begin{tabular}{|c|c|c|c|c|c|c|}
\hline & \multicolumn{2}{|c|}{ Higher protein formula } & \multicolumn{2}{|c|}{ Lower protein formula } & \multicolumn{2}{|c|}{ Breast-fed } \\
\hline & $n$ & $\%$ & $n$ & $\%$ & $n$ & $\%$ \\
\hline$N$ & \multicolumn{2}{|c|}{170} & \multicolumn{2}{|c|}{184} & \multicolumn{2}{|c|}{$184^{*}$} \\
\hline Boys/girls $(n)$ & \multicolumn{2}{|c|}{$90 / 80$} & \multicolumn{2}{|c|}{$87 / 97$} & \multicolumn{2}{|c|}{$79 / 105$} \\
\hline \multicolumn{7}{|l|}{ Delivery } \\
\hline Delivery type (\% vaginal $/ \%$ caesarean) & \multicolumn{2}{|c|}{$77 \cdot 4 / 22 \cdot 6$} & \multicolumn{2}{|c|}{$66 \cdot 1 / 33 \cdot 9^{\star}$} & \multicolumn{2}{|c|}{$85 \cdot 9 / 14 \cdot 1^{\star, b}$} \\
\hline \multicolumn{7}{|l|}{ Gestational age (week of birth) } \\
\hline Mean & \multicolumn{2}{|c|}{39.8} & \multicolumn{2}{|c|}{$39 \cdot 7$} & \multicolumn{2}{|c|}{$40 \cdot 0^{\star, a}$} \\
\hline SD & \multicolumn{2}{|c|}{1.3} & \multicolumn{2}{|c|}{1.2} & \multicolumn{2}{|c|}{1.1} \\
\hline \multicolumn{7}{|l|}{ Mother's age at child's birth (years) } \\
\hline Mean & \multirow{2}{*}{\multicolumn{2}{|c|}{$\begin{array}{c}30.9 \\
4.7\end{array}$}} & \multicolumn{2}{|c|}{$30 \cdot 8$} & \multicolumn{2}{|c|}{$31 \cdot 5^{\star, a}$} \\
\hline SD & & & & & & \\
\hline \multicolumn{7}{|l|}{ Anthropometry } \\
\hline Birth weight (g) & 3278 & 347 & 3245 & 313 & 3319 & $355^{\mathrm{a}}$ \\
\hline Birth length $(\mathrm{cm})$ & 50.5 & $2 \cdot 7$ & $50 \cdot 5$ & $2 \cdot 6$ & $51 \cdot 0$ & 2.6 \\
\hline Head circumference $(\mathrm{cm})$ & $34 \cdot 1$ & 1.4 & $34 \cdot 1$ & 1.3 & $34 \cdot 2$ & 1.3 \\
\hline \multicolumn{7}{|l|}{ Maternal habits ( $\%$ no/ $\%$ yes) } \\
\hline Smoked $\leq 12$ weeks gestation ( $\%$ no/ $\%$ yes) & \multicolumn{2}{|c|}{$81 \cdot 8 / 18 \cdot 2$} & \multicolumn{2}{|c|}{$69 \cdot 8 / 30 \cdot 2 \dagger$} & & \\
\hline Smoked $>12$ weeks gestation & & & & & & \\
\hline Alcohol during pregnancy & & & & & & \\
\hline Stress during pregnancy & & & & & & \\
\hline Socio-demographic characteristics & & & & & & \\
\hline Mother's education level & & & & & & \\
\hline Low & $32 \ddagger$ & $18 \cdot 8$ & $44 \ddagger$ & $24 \cdot 3$ & $12 \ddagger$ & 6.5 \\
\hline Middle & $92 \ddagger$ & $54 \cdot 1$ & $97 \ddagger$ & $53 \cdot 6$ & $82 \ddagger$ & $44 \cdot 6$ \\
\hline High & $46 \ddagger$ & $27 \cdot 1$ & $40 \ddagger$ & $22 \cdot 1$ & $90 \ddagger$ & 48.9 \\
\hline Father's education level & & & & & & \\
\hline Low & $46 \ddagger$ & $27 \cdot 2$ & $53 \ddagger$ & $29 \cdot 37$ & $18 \ddagger$ & 9.8 \\
\hline Middle & $94 \ddagger$ & $55 \cdot 6$ & $88 \ddagger$ & $48 \cdot 6$ & $76 \ddagger$ & 41.3 \\
\hline High & $29 \ddagger$ & $17 \cdot 2$ & $40 \ddagger$ & $22 \cdot 1$ & $90 \ddagger$ & 48.9 \\
\hline Parents' highest education level & & & & & & \\
\hline Low & $22 \ddagger$ & $12 \cdot 9$ & $29 \ddagger$ & $15 \cdot 9$ & $7 \ddagger$ & 3.4 \\
\hline Medium & $91 \ddagger$ & 53.5 & $98 \ddagger$ & 53.8 & $76 \ddagger$ & 36.9 \\
\hline High & $57 \ddagger$ & 33.5 & $55 \ddagger$ & $30 \cdot 2$ & $123 \ddagger$ & 59.7 \\
\hline Both parents foreigner (no/yes (\%)) & & & & & & \\
\hline Single mother (no/yes (\%)) & & & & & & \\
\hline
\end{tabular}

HP, higher protein; LP, lower protein.

${ }^{\star} P<0.05, \dagger P<0.01, \ddagger P<0.001$ v. HP; ${ }^{a} P<0.05,{ }^{b} P<0.001$ v. LP.

\section{Discussion}

This study aimed to assess the effect of feeding healthy, term infants with different amounts of protein (within the accepted range) during the 1st year of life (a critical period for brain growth and development) on mental performance later in life (at 8 years of age). To pose this question, we depended on the existing literature showing improved mental performance among preterm and under-nourished children who had been protein supplemented. The importance of such studies lies on the recent trends towards LP intake recommendations ${ }^{(13)}$ - for example, to prevent obesity risk. In this context, it was demonstrated that LP content in infant formulae within the normal ranges $^{(16)}$ reduced the later obesity risk (by achieving significant lower BMI at 2 years), but did not have any negative effect on length ${ }^{(14)}$. In a scenario where reduced protein intake is recommended, and this reduction seems to have preventive effects on obesity but not deleterious effects on growth, it remains a necessity to carry out a safety analysis confirming the similar neurodevelopment in childhood of those who have been fed a LP formula in early life. To test this hypothesis, we selected an extensive neuropsychological battery of tests for different domains and functions rather than a test assessing overall ability (i.e. intelligence quotient). In nutrition studies, one particular domain may be affected differently than others at different ages, and an overall ability test may not detect these differential patterns ${ }^{(43,44)}$.

The results from this randomised clinical trial show no significant differences between 8-year-old children who had been fed the lower and the HP content formula during the 1st year of life in memory (verbal and visual), attention (spatial, focused and sustained), perception, language (fluency and comprehension), processing speed, motor coordination and executive functions (shifting/flexibility), inhibition/impulsivity, working memory, reasoning, selective and focused attention, visual-spatial skills or decision making, confirming the safety of the LP content formula.

Previous studies reporting different mental performances in children fed HP intakes ${ }^{(3,8,9,11,12)}$ had been undertaken in special populations with special needs, but not in in-term, wellnourished children.

We did not find any difference in mental performance between the formula-fed groups and the BF group. Taking into account that $\mathrm{BF}$ children are considered as a gold standard of 


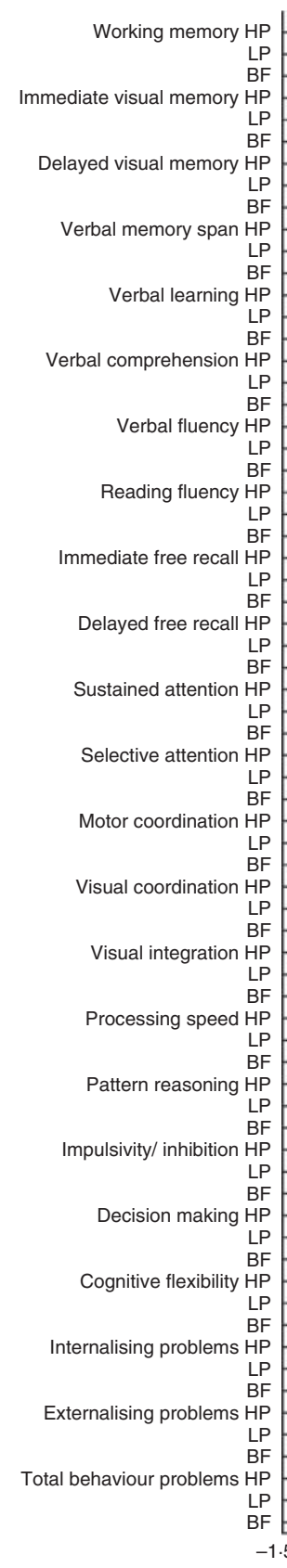

Early protein intake and mental performance

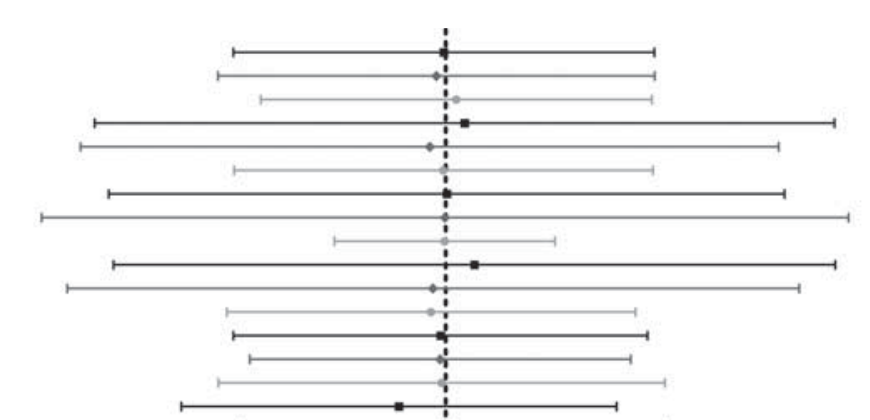


The main strengths of our study are the randomised clinical trial design, the large multi-European country sample and the extensive neuropsychological battery of tests used to assess different domains and functions.

In summary, herewith we report on the safety of LP content in infant formulae (closer to the content of human milk) according to long-term mental performance.

\section{Acknowledgements}

The authors gratefully acknowledge participants for their enthusiastic support to the study, Cristina Campoy for her efforts to coordinate the Nutrimenthe Project, Miguel Pérez-Garcia (UGR) for the design of the neuropsychological battery of tests and advice with its use and Ainara Blanco (URV) for her contribution to the fieldwork.

The studies reported here have been carried out with partial financial support from the Commission of the European Communities, specific RTD Programme 'Quality of Life and Management of Living Resources', within the 5th Framework Programme, research grants no. QLRT-2001-00389 and QLK1-CT-2002-30582, and the 7th Framework Programme (FP7/2008-2013), under grant agreement $\mathrm{n}^{\mathbf{o}} 212652$ (NUTRIMENTHE Project 'The Effect of Diet on the Mental Performance of Children', the contract FP7-289346-EARLY NUTRITION and the European Research Council Advanced Grant ERC-2012-AdG - no. 322605 META-GROWTH. This manuscript does not necessarily reflect the views of the Commission and in no way anticipates the future policy in this area. The participating company had no decisive role in the conduct and analysis of the study. The formula for the study was produced by Bledina (Villefranche-sur-Saône Cédex, France, part of Danone Baby Nutrition), who operated as a partner of this EU project and received a grant from the EU Commission for this task. No funding bodies had any role in the study design, data collection and analysis, decision to publish or preparation of the manuscript.

The authors' responsibilities were as follows: J. E. and V. L. contributed equally as first authors of the final version; R.C.-M., J. E., B. K., E. R. and D. G. conceived and designed the research; V. L., E. V., K. S., N. F. and G. B. acquired data; M. W. and V. G. managed data and advised the statistical analyses; V. L. performed the statistical analyses and drafted the article; and F. C. and J. E. revised the article for important intellectual content; all the authors read and gave their final approval of the version to be published.

There are no conflicts of interest.

This paper was published as a supplement in the British Journal of Nutrition, the publication of which was supported by the Nutrimenthe Consortium. The paper has undergone the standard journal formal review.

\section{Supplementary Material}

For supplementary material/s referred to in this article, please visit http://dx.doi.org/10.1017/S0007114515000768

\section{References}

1. Dobbing J (1981) Nutritional Growth Restriction and the Nervous System. In The Molecular Basis of Neuropathology, pp. 221-223 [Davison AN and Thompson RHN, editors]. London: Edward Arnold.

2. Mwaniki MK, Atieno M, Lawn JE, et al. (2004) Long-term neurodevelopmental outcomes after intrauterine and neonatal insults: a systematic review. Lancet 379, 445-452.

3. Laus MF, Vales LD, Costa TM, et al. (2011) Early postnatal protein-calorie malnutrition and cognition: a review of human and animal studies. Int J Environ Res Public Health 8, 590-612.

4. Kretchmer N, Beard JL \& Carlson S (1996) The role of nutrition in the development of normal cognition. Am J Clin Nutr $\mathbf{6 3}$, 997S-1001S.

5. Georgieff MK (2007) Nutrition and the developing brain: nutrient priorities and measurement. Am J Clin Nutr 85, 614S-620S.

6. De Souza AS, Fernandes FS \& do CM (2011) Effects of maternal malnutrition and postnatal nutritional rehabilitation on brain fatty acids, learning, and memory. Nutr Rev 69, 132-144.

7. Currenti SA (2010) Understanding and determining the etiology of autism. Cell Mol Neurobiol 30, 161-171.

8. Lucas A, Morley R \& Cole TJ (1998) Randomised trial of early diet in preterm babies and later intelligence quotient. BMJ 317, 1481-1487.

9. Grantham-McGregor Baker-Henningham H (2005) Review of the evidence linking protein and energy to mental development. Pub Health Nutr 87, 1191-1201.

10. Pollitt E, Saco-Pollitt C, Jahari A, et al. (2000) Effects of an energy and micronutrient supplement on mental development and behavior under natural conditions in undernourished children in Indonesia. Eur J Clin Nutr 54, Suppl. 2, S80-S90.

11. Pollitt E, Gorman KS, Engle PL, et al. (1993) Early supplementary feeding and cognition: effects over two decades. Monogr Soc Res Child Dev 1993, 1-99.

12. Li H, Barnhart HX, Stein AD \& Martorell R (2003) Effects of early childhood supplementation on the educational achievement of women. Pediatrics 2003, 1156-1162.

13. World Health Organization (2007) Protein and amino acid requirements of infants and children. Joint WHO/FAO/UNU Expert Consultation. WHO Technical Report Serial no. 935. Geneva: WHO Press, 175-177.

14. Koletzko B, von Kries R, Closa R, et al. (2009) Lower protein in infant formula is associated with lower weight up to age $2 \mathrm{y}$ : a randomized clinical trial. Am J Clin Nutr 89, 1836-1845.

15. Weber M, Grote V, Closa-Monasterolo R, et al. (2014) Lower protein content in infant formula reduces BMI and obesity risk at school age: follow-up of a randomized trial. Am J Clin Nutr (In the press).

16. European Commission (1991) Commission Directive 91/321/ EEC of 14 May 1991 on infant and follow-on formulae. Off J Eur Comm 175, 35-49.

17. Aggett PJ, Agostoni C, Goulet O, et al. (2001) The nutritional and safety assessment of breast milk substitutes and other dietary products for infants: a commentary by the ESPGHAN Committee on Nutrition. J Pediatr Gastroenterol Nutr 32, 256-258.

18. Snodgrass J \& Vanderwart M (1980) A standardized set of 260 pictures: norms for name agreement, image agreement, familiarity, and visual complexity. J Exp Psychol Hum Learn 6, 174.

19. Rey A (1941) The psychological evaluation in case of traumatic encephalopathy. Arch Psychol (Geneve) 28, 21.

20. De Sousa-Magalhães S, Fernandes-Malloy-Diniz L \& Cavalheiro-Hamdan A (2012) Validity convergent and reliability test-retest of the rey auditory verbal learning test. Clin Neuropsychiatry 9, 129-137. 
21. Conners CK, Epstein JN, Angold A, et al. (2003) Continuous performance test performance in a normative epidemiological sample. J Abnorm Child Psychol 31, 555-562.

22. Conners CK. (1985) The computerized continuous performance test. Psychopharmacol Bull 21, 891-892.

23. Woodcock R \& Muñoz-Sandoval A (1996) WoodcockMuñoz battery: cognitive ability tests-Revised. Itasca, IL: Riverside Publishing.

24. Woodcock R \& Muñoz-Sandoval A (1993) Comprehensive Manual. Woodcock-Muñoz Language Survey: English Form. Itasca, IL: Riverside Publishing.

25. Woodcock R, McGrew K \& Mather N (2001) WoodcockJohnson III Tests of Cognitive Abilities. Itasca, IL: Riverside Publishing.

26. McGrew KS \& Woodcock RW (2001) Technical manual. Woodcock-Johnson III. Itasca, IL: Riverside Publishing.

27. Hooper H (1983) Hooper Visual Organization Test Manual. Torrance, CA: Western Psychological Services.

28. Lopez MN, Lazar MD \& Oh S (2003) Psychometric properties of the Hooper Visual Organization Test. Assessment 10, 66-70.

29. Korkman M, Kirk U \& Kemp SL (2007) NEPSY II. Administrative Manual. San Antonio, TX: Psychological Corporation.

30. Korkman M, Kirk U \& Kemp SL., NEPSY II (2007) Clinical and Interpretative Manual. San Antonio, TX: Psychological Corporation.

31. Smith A. (2007) Symbol Digit Modalities Test, 10th printing, ed. Torrance, CA: WPS Western Psychological Services.

32. Grooved Pegboard user instructions (2002) Lafayette Instruments.

33. Golden C (1978) Stroop Color and Word Test. Illinois: Stoelting Company.

34. Kaufman A \& Kaufman N (2004) Kaufman Assessment Battery for Children, 2nd ed. Minneapolis: Pearson.

35. Llorente A, Williams J, Satz P, et al. (2003) Children's Color Trails Test. Lutz, FL: PAR Psychological Assessment Resources, Inc

36. Crone EA \& van der Molen MW (2004) Developmental changes in real life decision making: performance on a gambling task previously shown to depend on the ventromedial prefrontal cortex. Dev Neuropsychol 25, 251-279.

37. Achenbach TM \& Rescorla LA (2001) Manual for the ASEBA School-Age Forms and Profiles. Burlington: University of Vermont Department of Psychiatry.

38. Achenbach TM (1991) Manual for the Child Behavior Checklist/4-18 and Profiles. Burlington: University of Vermont Department of Psychiatry.

39. UIS. International Standard Classification of Education: ISCED 1997 (2006) Montreal, Canada: UNESCO Library Report no.: UIS/TD/06-01.
40. World Medical Association (2000) Declaration of Helsinki: ethical principles for medical research involving human subjects. JAMA 284, 3043-3045.

41. World Health Organization (2007) WHO Multicentre Growth Reference Study Group. WHO Child Growth Standards: Methods and development: Head Circumference-For-Age, Arm Circumference-For-Age, Triceps Skinfold-For-Age and Subscapular Skinfold-For-Age. Geneva: WHO Press.

42. WHO (2009) WHO Anthro software for PC [computer program].

43. Schmitt JA, Benton D \& Kallus KW (2005) General methodological considerations for the assessment of nutritional influences on human cognitive functions. Eur J Nutr $\mathbf{4 4}$, 459-464.

44. Isaacs E \& Oates J (2008) Nutrition and cognition: assessing cognitive abilities in children and young people. Eur J Nutr 47, Suppl. 3, 4-24.

45. Nyaradi A, Li J, Hickling S, Foster J, et al. (2013) The role of nutrition in children's neurocognitive development, from pregnancy through childhood. Front Hum Neurosci 7, 97.

46. Isaacs EB, Gadian DG, Sabatini S, Chong WK, Quinn BT, Fischl BR, et al. (2008) The effect of early human diet on caudate volumes and IQ. Pediatr Res 63, 308-314.

47. Kafouri S, Kramer M, Leonard G, Perron M, et al. (2013) Breastfeeding and brain structure in adolescence. Int $J$ Epidemiol 42, 150-159.

\section{Appendix: European Childhood Obesity Project Group}

Beyer J., Fritsch M., Grote V., Haile G., Handel U., Hannibal I., Koletzko B., Kreichauf S., Pawellek I., Schiess S., Verwied-Jorky S., von Kries R., Weber M. (Children's University Hospital, University of Munich Medical Centre, Munich, Germany), Dobrzańska A., Gruszfeld D., Janas R., Wierzbicka A., Socha P., Stolarczyk A., Socha J., (Children's Memorial Health Institute, Warsaw, Poland), Carlier C., Dain E., Goyens P., Van Hees J. N., Hoyos J., Langhendries J. P., Martin F., Poncelet P., Xhonneux A., (ULB Bruxelles and CHC St Vincent Liege), Perrin, E. (Danone Research Centre for Specialised Nutrition, Schiphol, The Netherlands), Agostoni C., Giovannini M., Re Dionigi A., Riva E., Scaglioni S., Vecchi F., Verducci E. (University of Milan), Closa-Monasterolo R., Escribano J., Blanco A., Canals F., Cardona M., Ferré N., Gispert-Llauradó M., Luque V., Mendez-Riera G., Rubio-Torrents M. C., Zaragoza-Jordana M. (URV). 